\title{
Age-dependent variations of cancellous bone in response to ovariectomy in $\mathrm{C57} \mathrm{BL} / 6 \mathrm{~J}$ mice
}

\author{
SHENG ZHOU $^{1 *}$, GUANGHU WANG $^{1 *}$, LIANG QIAO $^{1}$, QITING GE $^{2}$, DONGYANG CHEN $^{1}$, ZHIHONG XU $^{1}$, \\ DONGQUAN SHI ${ }^{1}$, JIN DAI ${ }^{1}$, JINZHONG QIN ${ }^{2}$, HUAJIAN TENG ${ }^{1,2}$ and QING JIANG ${ }^{1,2}$ \\ ${ }^{1}$ The Center of Diagnosis and Treatment for Joint Disease, Drum Tower Hospital, Medical School, \\ Nanjing University, Nanjing, Jiangsu 210008; ${ }^{2}$ Joint Research Center for Bone and Joint Disease, \\ Model Animal Research Center (MARC), Nanjing University, Nanjing, Jiangsu 210061, P.R. China
}

Received January 18, 2017; Accepted December 21, 2017

DOI: $10.3892 /$ etm.2018.5839

\begin{abstract}
The ovariectomized (OVX) mouse model has been widely accepted to be suitable for the study of postmenopausal osteoporosis. However, whether C57BL/6J mice, a commonly used genetic background mouse strain, is an appropriate model for postmenopausal osteoporosis remains controversial. The present study investigated the effect of the OVX model on alterations in bone density and microarchitecture in C57BL/6J female mice of different ages. C57BL/6J mice were divided into 8-, 12- and 16-week-old groups $\left(\mathrm{OVX}_{8}, \mathrm{OVX}_{12}\right.$ and $\mathrm{OVX}_{16}$ ) from the beginning of OVX. At 8 weeks post-surgery, the mice were anesthetized and micro-computed tomography was used to analyze the bone density and microarchitecture. The results revealed that OVX-induced loss of cancellous bone was greatest in $\mathrm{OVX}_{8}$, moderate in $\mathrm{OVX}_{12}$, and only a weak bone loss was observed in the $\mathrm{OVX}_{16}$ group when compared with the $\mathrm{SHAM}_{16}$ control group. In addition, the effect of genetic backgrounds in response to the OVX model were examined. Several other strains of mice, including inbred (BALB/c) and outbred (ICR and Kunming), were used in the present study, all of which were subjected to OVX at 8 weeks of age. The present findings revealed that the highest rate of bone loss was detected in C57BL/6J female mice. In addition, treatment with estrogen (17 $\beta$-estradiol, $30 \mu \mathrm{g} / \mathrm{kg}$ five times per week) led to a significant increase in bone density in C57BL/6J mice compared with the other strains of mice. Therefore, these results may provide novel insights into the age- and
\end{abstract}

Correspondence to: Professor Qing Jiang or Dr Huajian Teng, The Center of Diagnosis and Treatment for Joint Disease, Drum Tower Hospital, Medical School, Nanjing University, 321 Zhongshan Road, Nanjing, Jiangsu 210008, P.R. China

E-mail: tenghj@hotmail.com

E-mail: qingj@nju.edu.cn

${ }^{*}$ Contributed equally

Key words: C57BL/6J, ovariectomy, postmenopausal osteoporosis, bone density, bone microarchitecture strain-associated effect of OVX on regulating turnover of bone in female mice. The present findings also suggest 8-week-old C57BL/6J mice as an animal model for postmenopausal osteoporosis and preclinical testing of potential therapies for this disease.

\section{Introduction}

Postmenopausal osteoporosis is characterized by a decrease in bone mass and a deterioration in bone architecture. The lifetime risk for women to have an osteoporotic fracture is $30-40 \%$ worldwide (1), which has a notable social, physical and economic impact (2-5).

Experimental animal models have contributed tremendously to knowledge of the pathophysiology and treatment targets of postmenopausal osteoporosis. The ovariectomy (OVX) rat is the most commonly used animal model for evaluating the mechanisms underlying postmenopausal osteoporosis and therapeutic strategies for treating this disease (6-9). However, compared with rats, mice may be a more effective model as they have a more easily manipulated genome and lower drug doses are required for treatment. Several strains of mice have been used in postmenopausal osteoporosis research (10-13). However, there are controversies regarding the use of C57BL/6J mice as an animal model for postmenopausal osteoporosis (14-16). The starting age of C57BL/6J mice subjected to ovariectomy varies from 4 to 30 weeks old (10,15-18). Certain combinations of age, skeletal site and time post-surgery may lead to varying levels of bone alterations in response to estrogen deficiency in female rats (6). It is reasonable to hypothesize that the starting age may result in varying levels of bone deterioration upon estrogen deficiency in $\mathrm{C} 57 \mathrm{BL} / 6 \mathrm{~J}$ mice. Therefore, to improve the understanding of disease pathogenesis and to develop novel therapies, further characterization of $\mathrm{C} 57 \mathrm{BL} / 6 \mathrm{~J}$ mice as an animal model for postmenopausal osteoporosis is required.

The current study investigated whether C57BL/6J mice were a valid model for postmenopausal osteoporosis. Mice were used in three different age groups $(8,12$ and 16 weeks old) to evaluate the extent of bone loss in response to OVX by micro-computed tomography $(\mu \mathrm{CT})$. To further evaluate bone mass changes of $\mathrm{C} 57 \mathrm{BL} / 6 \mathrm{~J}$ mice in response to OVX and 
estrogen replacement, the inbred strain (BALB/c) and outbred strains (ICR and Kunming) of mice were used in this study, and OVX was performed in those mice at 8 weeks of age.

\section{Materials and methods}

Animals. Female C57BL/6J mice (8, 12 and 16 weeks old). The total number of 8-, 12- and 16-week-old mice was 26,21 and 22 , respectively. The range of body weight of 8-, 12- and 16-week-old mice was 16.3-20.3, 15.9-24.7 and 20.7-25.6 g, respectively), and female BALB/c, ICR and Kunming mice (all 8 weeks old). The total number of BALB/c, ICR and Kunming was 24, 28 and 28, respectively. The range of body weight of BALB/c, ICR and Kunming mice was 20.9-27.5, 26.5-32 and 32.4-41.8 g, respectively) were purchased from Cavens Biological Technology Co., Ltd., Nanjing, China, https://www. biomart.cn/56079/index.htm. All mice were maintained under a 12-h light/dark cycle at room temperature $\left(22 \pm 2^{\circ} \mathrm{C}\right)$ with a humidity of $45 \%$ and allowed ad libitum access to water and standard rodent chow. All animal procedures were approved by the Animal Care and Use Committee of the Model Animal Research Center of Nanjing University (Nanjing, China).

Ovariectomy and estrogen supplement. Ovariectomy was conducted in 8-, 12- and 16-week-old female C57BL/6J mice and 8-week-old female BALB/c, ICR and Kunming mice. Mice were assigned to the following groups (Table I): Baseline, sacrificed at the corresponding age; SHAM, were subjected to sham operation; OVX, received bilateral ovariectomy; and OVX $+17 \beta$-estradiol (E2), at 1 week following surgery administered E2 (30 $\mu \mathrm{g} / \mathrm{kg}$; Sigma-Aldrich; Merck KGaA, Darmstadt, Germany; cat no. E2758) subcutaneously five times per week for 7 weeks. The dose of E2 used was similar to the levels used in a previous study where $20 \mu \mathrm{g} / \mathrm{kg} /$ day resulted in a serum E2 concentration that was similar to the levels in SHAM-operated mice (19). C57BL/6J mice were divided into 8-, 12- and 16-week-old groups $\left(\mathrm{OVX}_{8}, \mathrm{OVX}_{12}\right.$ and $\mathrm{OVX}_{16}$, respectively) from the beginning of OVX. BALB/c, ICR and Kunming mice were subject to surgery at the age of 8 weeks old $\left(\mathrm{OVX}_{8}\right)$. Surgery was conducted at the Model Animal Research Center of Nanjing University by two operators (SZ and GHW), who were skilled in OVX. In brief, animals were anesthetized (100 mg/kg ketamine, purchased from Fujian Gutian Pharmaceutical Co., Ltd., Fujian, China, http://www. fjgtyy.com/; and $5 \mathrm{mg} / \mathrm{kg}$ xylazine, purchased from Jilin Huamu Animal Health Product Co., Ltd., Jilin, China) for $\sim 1$ h. For the OVX group, anterior uterine horns were cut to remove the ovaries; for the SHAM group dorsoventral incisions were made through the skin, muscles and periosteum without removal of the ovaries. At 8 weeks post-surgery, animals were sacrificed by inhalation of $\mathrm{CO}_{2}$ and left femurs were harvested for $\mu \mathrm{aT}$ analysis. The uteri were excised and weighed.

$\mu C T$ analysis. Isolated left femurs were fixed with $4 \%$ paraformaldehyde for $24 \mathrm{~h}$ at $4^{\circ} \mathrm{C}$. Then, femurs were placed in plastic tubes and stored within the animal bed inside the SkyScan1176 (Bruker Corporation, Billerica, MA, USA). Femurs were scanned using an $18 \mu$. resolution protocol: $(45 \mathrm{kV}, 556 \mu \mathrm{A}, 0.1-\mathrm{mm} \mathrm{Cu}$ filter, and $0.2^{\circ}$ rotation step, 7 -min scan). Volumetric reconstruction software NRecon version 1.5 (Bruker Corporation) was used to reconstruct CT images. Quantification of bone mineral density and trabecular morphometric parameters was performed in a hand-picked cancellous bone area within the primary ossification center. The analyzed area was $0-2 \mathrm{~mm}$ above the distal growth plate (Fig. 1). The analysis was performed using scanner software (CTAn, Version 1.13, Bruker Corporation, Billerica, MA, USA). Trabecular parameters were as follows: Trabecular volumetric bone mineral density [vBMD; mg hydroxyapatite $(\mathrm{HA}) / \mathrm{cm}^{3}$ ], bone volume fraction (BV/TV; \%), trabecular thickness (Tb.Th; $\mathrm{mm}$ ), trabecular number (Tb.N; 1/mm), trabecular separation ( $\mathrm{Tb}$. $\mathrm{Sp} ; \mathrm{mm}$ ), structure model index (SMI) and connectivity density (Conn.D; $1 / \mathrm{mm}^{3}$ ). The present study evaluated an area $1 \mathrm{~mm}$ above and below the midline of the femur to measure the bone mineral density (cortical BMD; $\mathrm{mg} \mathrm{HA} / \mathrm{cm}^{3}$ ) and cross-sectional thickness (Cs.Th; mm) of cortical bone (Fig. 1).

Statistical analysis. The effect of age on the body weight, trabecular and cortical bone properties in $\mathrm{C} 57 \mathrm{BL} / 6 \mathrm{~J}$ were identified using one-way analysis of variance and followed by Fisher's least significant difference (LSD) if the variance was equal, otherwise Dunnett's post hoc test was performed. To ascertain whether bone loss in C57BL/6J following OVX was influenced by age, a two-way analysis of variance followed by Bonferroni's post hoc test was used with treatment (SHAM vs. OVX) and age. An unpaired Student's t-test was used to compare body weight and bone morphology between SHAM and OVX to detect OVX effects in three different age C57BL/6J groups.

To compare the body mass and skeletal parameter differences among the inbred and outbred mice strains, the values of baseline were compared using a one-way analysis of variance followed by an LSD post hoc test if the variance was equal, otherwise Dunnett's post hoc test was used. To evaluate whether bone loss following OVX or bone gain following subsequent E2 treatment was influenced by genetic factors, a two-way analysis of variance followed by Bonferroni's post hoc test was used with treatment (SHAM vs. OVX, or OVX vs. OVX+ E2) and strain. An unpaired Student's t-test was used to compare body weight and bone morphology between SHAM and OVX, or OVX and OVX+E2 to detect OVX or estrogen supplement effects among inbred and outbred mice.

All statistical tests were performed using SPSS version 17.0 software (SPSS, Inc., Chicago, IL, USA) and P $<0.05$ was considered to indicate a statistically significant difference. Data are presented as the mean \pm standard error.

\section{Results}

Age-associated alterations in body weight, distal femur trabecular and femoral mid-shaft cortical bone density and architecture in C57BL/6J female mice by $\mu C T$. Age-associated alterations of body weight and distal femur metaphyseal trabecular architecture in $\mathrm{C} 57 \mathrm{BL} / 6 \mathrm{~J}$ female mice are presented in Table II. The body weight of C57BL/6J mice increased steadily with age from $8-24$ weeks old by $43.9 \%(\mathrm{P}<0.05)$. Trabecular vBMD plateaued from 8-16 weeks and declined thereafter. Cancellous BV/TV decreased continuously from 12-24 weeks of age. A similar trend was found in Tb.Th, Tb.N and Conn.D (a measure of trabecular connectedness). Correspondingly, $\mathrm{Tb} . \mathrm{Sp}$ followed an opposite pattern of alterations. SMI remained relatively constant from 8-16 weeks of age, but were 
Table I. Number of mice in each group.

\begin{tabular}{lcccc}
\hline Group & Baseline mice (n) & SHAM mice (n) & OVX mice (n) & OVX + E2 mice (n) \\
\hline 8-week old C57BL/6 & 6 & 6 & 7 & 7 \\
12-week old C57BL/6 & 8 & 6 & 6 & - \\
16-week old C57BL/6 & 8 & 6 & 6 & - \\
8-week old BALB/c & 6 & 6 & 7 & 6 \\
8-week old ICR & 7 & 8 & 7 & 7 \\
8-week old Kunming & 7 & 7 & & 6 \\
\hline
\end{tabular}

E2, 17ß-estradiol; OVX, ovariectomized.

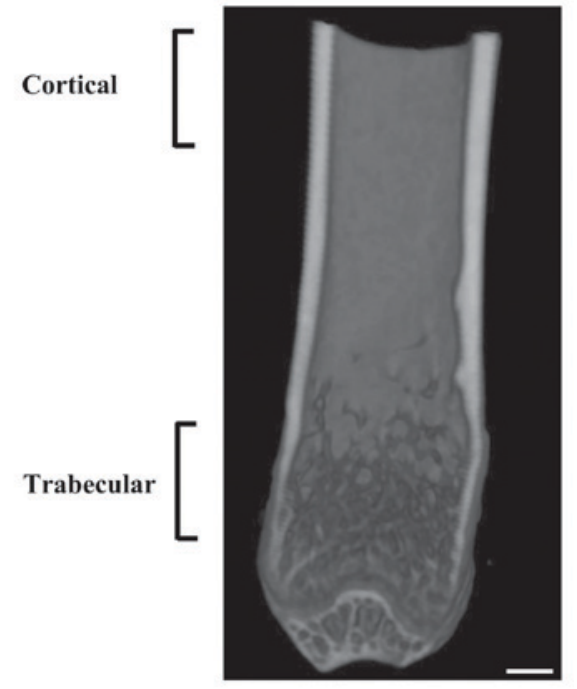

Figure 1. A three-dimensional model of the distal femur is shown. Brackets define the trabecular and cortical regions chosen for analysis. Scale bar=1 $\mathrm{mm}$.

increased significantly at 20 ( $\mathrm{P}<0.05$ vs. 8,12 and 16 weeks) and 24 weeks $(\mathrm{P}<0.05$ vs. 12 and 16 weeks $)$, indicative of a shift to a more rod-like architecture.

Age-related changes in the mid-femur diaphysis are also presented in Table II. Cortical BMD and Cs.Th increased continuously with age; the largest increase occurred between 8 and 12 weeks, and measurements plateaued thereafter.

Influence of age on the sensitivity to estrogen deprivation in C57BL/6J female mice. When mice were sacrificed, the abdominal cavity was explored. The ovaries could not be located and the uteruses were very small, which indicated that OVX mice had their ovaries removed. As expected, $\mathrm{OVX}_{8}$, $\mathrm{OVX}_{12}$ and $\mathrm{OVX}_{16}$ were also heavier than mice in the SHAM group, although there was not a significant difference between $\mathrm{OVX}_{16}$ and SHAM groups $(\mathrm{P}<0.01, \mathrm{P}<0.05$ and $\mathrm{P}=0.057$, respectively; Table III).

The patterns of microarchitectural deterioration in response to OVX varied among the three age groups (Table III). In general, microarchitectural deterioration was severe in $\mathrm{OVX}_{8}$, intermediate in $\mathrm{OVX}_{12}$ and lowest in $\mathrm{OVX}_{16}$. This was highlighted by significant differences between OVX and SHAM across the parameters examined in $\mathrm{OVX}_{8}$, with the exception of Tb.Th and SMI. For trabecular vBMD, Tb.Sp and Conn.D in the distal femur, the response to OVX depended on the age, as determined by two-way analysis of variance analyses between treatment and age $\left(\mathrm{P}_{\text {treatment*age }}=0.016, \mathrm{P}_{\text {treatment*age }}<0.001\right.$, $\mathrm{P}_{\text {treatment*age }}=0.035$, respectively).

Upon ovariectomy, trabecular vBMD in all OVX groups was significantly reduced relative to their SHAM counterparts with $\mathrm{OVX}_{8}$ demonstrating the greatest reduction $(-35.1 \%)$. $\mathrm{BV} / \mathrm{TV}$ declined significantly in $\mathrm{OVX}_{8}(-64.2 \%, \mathrm{P}=0.0078$ vs. SHAM) and $\mathrm{OVX}_{12}(-47.1 \%, \mathrm{P}=0.0496$ vs. SHAM) and declined non-significantly in $\mathrm{OVX}_{16}(-31.2 \%, \mathrm{P}=0.1834$ vs. SHAM). For Tb.Th, there were no marked alterations in all age groups. All age groups exhibited a decline in Tb.N, ranging from -34.7 to $-62.9 \%$, but this decline was only statistically significant in $\mathrm{OVX}_{8}\left(-62.9 \%, \mathrm{P}=0.0017\right.$ vs. SHAM) and $\mathrm{OVX}_{12}$ $(-37.3 \%, \mathrm{P}=0.0184$ vs. SHAM). No significant alterations in SMI existed among the three groups. Conn.D decreased significantly in $\mathrm{OVX}_{8}(-61.9 \%, \mathrm{P}=0.0008$ vs. SHAM) and $\mathrm{OVX}_{12}(-56.6 \%, \mathrm{P}=0.0108$ vs. SHAM $)$, but $\mathrm{OVX}_{16}$ exhibited a non-significant decrease.

The effect of OVX on mid-femoral cortical bone did not appear to depend on age (Table III). Cortical BMD exhibited a statistically significant decline in $\mathrm{OVX}_{12}(-3.5 \%, \mathrm{P}=0.028$ vs. SHAM) and $\mathrm{OVX}_{16}(-2.9 \%, \mathrm{P}=0.02$ vs. SHAM), except for $\mathrm{OVX}_{8}$. By contrast, Cs.Th only declined significantly in $\mathrm{OVX}_{8}$ $(-6.8 \%, \mathrm{P}=0.0114)$.

Differences in body mass and bone morphology among inbred and outbred strains of mice. To further explore the bone mass alterations in C57BL/6J mice in response to OVX and estrogen replacement, the above studies were extended by evaluating the inbred and outbred strains, and using an estrogen supplement.

At 8 weeks (baseline), body weight was highest in Kunming, intermediate in ICR and BALB/C, and lowest in C57BL/6J mice (Table IV). Femur trabecular bone in C57BL/6J mice was characterized by the lowest trabecular vBMD, BV/TV, Tb.Th, Tb.N and Conn.D, whereas these mice also exhibited the highest Tb.Sp and SMI. Kunming mice had the most trabeculae and consequently the least Tb.Sp. In trabecular regions, Tb.Th was significantly higher in BALB/c compared with ICR mice $(\mathrm{P}<0.05)$.

In the femoral cortical bone, BMD was significantly lower in $\mathrm{C} 57 \mathrm{BL} / 6 \mathrm{~J}$ than the other three strains of mice, whereas Cs.Th was highest in ICR and Kunming, intermediate in BALB/c and lowest in C57BL/6J (Table IV). 
Table II. Body weight, bone mass and microarchitecture in 8-, 12-, 16-, 20- and 24-week old female C57BL/6 mice.

\begin{tabular}{lccccc}
\hline Parameter & 8-week old & 12-week old & 16-week old & 20-week old & 24-week old \\
\hline Body weight $(\mathrm{g})$ & $17.49 \pm 0.30^{\mathrm{c}, \mathrm{e}}$ & $20.55 \pm 1.00^{\mathrm{e}}$ & $23.26 \pm 0.59^{\mathrm{a}}$ & $22.92 \pm 1.19$ & $25.16 \pm 0.902^{\mathrm{a}, \mathrm{b}}$ \\
Distal femur: Trabecular & & & & & \\
vBMD $\left(\mathrm{mgHA} / \mathrm{cm}^{3}\right)$ & $0.137 \pm 0.004$ & $0.137 \pm 0.006$ & $0.142 \pm 0.002^{\mathrm{e}}$ & $0.129 \pm 0.004$ & $0.123 \pm 0.005^{\mathrm{c}}$ \\
BV/TV $(\%)$ & $9.342 \pm 0.634$ & $14.361 \pm 2.151^{\mathrm{e}}$ & $12.983 \pm 0.912^{\mathrm{e}}$ & $8.118 \pm 1.402$ & $6.467 \pm 0.813^{\mathrm{b}, \mathrm{c}}$ \\
Tb.Th $(\mathrm{mm})$ & $0.074 \pm 0.002$ & $0.080 \pm 0.003^{\mathrm{d}}$ & $0.077 \pm 0.001^{\mathrm{d}}$ & $0.070 \pm 0.002^{\mathrm{b}, \mathrm{c}}$ & $0.073 \pm 0.002$ \\
Tb.N $\left(\mathrm{mm}^{-1}\right)$ & $1.253 \pm 0.074^{\mathrm{b}, \mathrm{c}}$ & $1.826 \pm 0.202^{\mathrm{a}, \mathrm{d}, \mathrm{e}}$ & $1.681 \pm 0.099^{\mathrm{a}, \mathrm{d}, \mathrm{e}}$ & $1.137 \pm 0.182^{\mathrm{a}-\mathrm{c}}$ & $0.875 \pm 0.096^{\mathrm{b}, \mathrm{c}}$ \\
Tb.Sp $(\mathrm{mm})$ & $0.359 \pm 0.029$ & $0.259 \pm 0.013^{\mathrm{e}}$ & $0.260 \pm 0.006^{\mathrm{e}}$ & $0.303 \pm 0.028$ & $0.329 \pm 0.014^{\mathrm{b}, \mathrm{c}}$ \\
SMI & $2.559 \pm 0.033^{\mathrm{e}}$ & $2.547 \pm 0.088^{\mathrm{d}, \mathrm{e}}$ & $2.537 \pm 0.057^{\mathrm{d}, \mathrm{e}}$ & $2.751 \pm 0.076^{\mathrm{b}, \mathrm{c}}$ & $2.779 \pm 0.067^{\mathrm{a}-\mathrm{c}}$ \\
Conn.D $\left(\mathrm{mm}^{-3}\right)$ & $41.546 \pm 4.465^{\mathrm{e}}$ & $69.722 \pm 1.015^{\mathrm{e}}$ & $55.104 \pm 0.508^{\mathrm{e}}$ & $41.531 \pm 0.781$ & $19.872 \pm 2.994^{\mathrm{a}-\mathrm{c}}$ \\
Femoral midshaft: Cortical & & & & & \\
BMD $\left(\mathrm{mgHA} / \mathrm{cm}^{3}\right)$ & $0.848 \pm 0.027^{\mathrm{b}-\mathrm{e}}$ & $1.064 \pm 0.008^{\mathrm{a}, \mathrm{c}-\mathrm{e}}$ & $1.107 \pm 0.008^{\mathrm{a}, \mathrm{b}, \mathrm{d}}$ & $1.163 \pm 0.009^{\mathrm{a}-\mathrm{c}}$ & $1.136 \pm 0.009^{\mathrm{a}, \mathrm{b}}$ \\
Cs.Th $(\mathrm{mm})$ & $0.138 \pm 0.002^{\mathrm{b}-\mathrm{e}}$ & $0.170 \pm 0.003^{\mathrm{a}, \mathrm{c}-\mathrm{e}}$ & $0.183 \pm 0.004^{\mathrm{a}, \mathrm{b}}$ & $0.182 \pm 0.006^{\mathrm{a}, \mathrm{b}}$ & $0.190 \pm 0.003^{\mathrm{a}, \mathrm{b}}$ \\
\hline
\end{tabular}

Data are presented as the mean \pm the standard error of the mean. ${ }^{a} \mathrm{P}<0.05$ vs. 8 -week old, ${ }^{b} \mathrm{P}<0.05$ vs. 12 -week old, ${ }^{\mathrm{c}} \mathrm{P}<0.05$ vs. 16 -week old, ${ }^{\mathrm{d}} \mathrm{P}<0.05$ vs. 20 -week old and ${ }^{\mathrm{e}} \mathrm{P}<0.05$ vs. 24 -week old. vBMD, volumetric bone mineral density; BV/TV, bone volume fraction; Tb.Th, trabecular thickness; Tb.N, trabecular number; Tb.Sp, trabecular separation; SMI, structure model index; Conn.D, connectivity density; Cs.Th, cross-sectional thickness; BMD, bone mineral density; HA, hydroxyapatite.

Influence of strain on the sensitivity to estrogen deprivation and supplement. $\mathrm{C} 57 \mathrm{BL} / 6 \mathrm{~J}$ and $\mathrm{BALB} / \mathrm{c}$ mice subjected to OVX exhibited significant increases $21.9 \%(\mathrm{P}=0.0001)$ and $6.5 \%(\mathrm{P}=0.0353)$ of their body mass compared with SHAM counterparts (Tables III and V). Only C57BL/6J and Kunming mice treated with estrogen exhibited significantly decreased body masses $(-8.3 \%, \mathrm{P}=0.0066 ;-4.8 \%, \mathrm{P}=0.0465$; respectively; Table VI).

All four strains of mice lost cancellous bone in the femur following OVX, with no treatment-strain interaction observed, except in Tb.Sp and Conn.D. $\left(\mathrm{P}_{\text {treatment* }{ }^{*} \text { age }}=0.007\right.$; $\mathrm{P}_{\text {treatment*age }}=0.035$, respectively; Tables III and V). Femur trabecular vBMD was lower in OVX than the SHAM group in all four strains of mice (Tables III and V). The effect of OVX on trabecular vBMD in C57BL/6J (-35.1\%, P<0.001 vs. SHAM) differed significantly from the effect in BALB/c $(-28.4 \%, \mathrm{P}<0.001$ vs. SHAM; $\mathrm{P}<0.001$ vs. $\mathrm{C} 57 \mathrm{BL} / 6 \mathrm{~J})$, ICR $(-31.2 \%, \mathrm{P}=0.002$ vs. SHAM; $\mathrm{P}=0.001$ vs. $\mathrm{C} 57 \mathrm{BL} / 6 \mathrm{~J})$ and Kunming $(-22.0 \%, \mathrm{P}=0.024$ vs. SHAM; $\mathrm{P}<0.001$ vs. C57BL/6J). Similar to femur trabecular vBMD, C57BL/6J exhibited the greatest decline in BV/TV $(-64.2 \%, \mathrm{P}=0.001$ vs. SHAM; Tables III and V). The other strains also exhibited a decline in femur BV/TV, ranging from -44.3 to $-54.9 \%$, but this decline was statistically significant only in $\mathrm{BALB} / \mathrm{c}$ $(\mathrm{P}<0.001$ vs. SHAM) and ICR $(\mathrm{P}=0.008$ vs. SHAM). A significant difference in Tb.Th between SHAM and OVX group was not detected in the $\mathrm{C} 57 \mathrm{BL} / 6 \mathrm{~J}$ strain, whereas BALB/c exhibited a $-15.4 \%$ decrease $(\mathrm{P}<0.001$ vs. SHAM $)$, ICR $-15.7 \%$ ( $\mathrm{P}=0.016$ vs. SHAM) and Kunming $-12.7 \%$ $(\mathrm{P}<0.001$ vs. SHAM). Tb.N decreased in C57BL/6J (-62.9\%, $\mathrm{P}=0.016$ vs. SHAM), BALB/c $(-47.6 \%, \mathrm{P}<0.001$ vs. SHAM), ICR $(-34.8 \%, \mathrm{P}=0.011$ vs. SHAM) and Kunming $(-36.0 \%$, $\mathrm{P}=0.013$ vs. SHAM). Tb.Sp increased in C57BL/6J (100\%, $\mathrm{P}<0.001$ vs. SHAM), BALB/c $(67.2 \%, \mathrm{P}=0.025$ vs. SHAM), ICR $(39.0 \%, P=0.023$ vs. SHAM) and Kunming (47.2\%,
$\mathrm{P}=0.026$ vs. SHAM). SMI increased significantly in $\mathrm{BALB} / \mathrm{c}$ $(26.5 \%, \mathrm{P}<0.001$ vs. SHAM) and ICR $(15.1 \%, \mathrm{P}=0.020$ vs. SHAM) whereas Conn.D declined in C57BL/6J (-61.9\%, $\mathrm{P}<0.001$ vs. SHAM) and ICR $(-31.5 \%, \mathrm{P}=0.042$ vs. SHAM). With regard to cortical bone indices, significant alterations were only found in C57BL/6J (Tables III and V). The difference in Cs.Th between SHAM and OVX mice was $-6.8 \%$ in $\mathrm{C} 57 \mathrm{BL} / 6 \mathrm{~J}$ mice $(\mathrm{P}=0.002$; Tables III and $\mathrm{V})$.

For $\mathrm{Tb} . \mathrm{Sp}$, the response to estrogen supplement was dependent on the strain $\left(\mathrm{P}_{\text {treatment"strain }}=0.02\right.$; Table VI). The alteration in this index following estrogen supplement differed significantly between $\mathrm{C} 57 \mathrm{BL} / 6 \mathrm{~J}$ and $\mathrm{BALB} / \mathrm{c}(\mathrm{P}=0.002)$, ICR $(\mathrm{P}=0.001)$ and Kunming $(\mathrm{P}=0.027)$. Notably, C57BL/6J mice were the only strain markedly responsive to estrogen supplement, demonstrating significant alterations in all parameters except for BV/TV and Conn.D. Whereas estrogen decreased $\mathrm{Tb} . \mathrm{Sp}$ by $31.9 \%$ in the metaphyseal trabecular bone of $\mathrm{C} 57 \mathrm{BL} / 6 \mathrm{~J}$ mice $(\mathrm{P}<0.001$ vs. OVX), it increased trabecular vBMD by $26.8 \%(\mathrm{P}=0.003$ vs. OVX; Table VI), BV/TV by $53.5 \%$ ( $\mathrm{P}=0.059$ vs. OVX; Table VI), Tb.Th by $14.2 \%(\mathrm{P}=0.045$ vs. $\mathrm{OVX})$ and $\mathrm{SMI}$ by $8.1 \%(\mathrm{P}=0.014$ vs. OVX). In the mid-femoral cortical bone of C57BL/6J mice, estrogen increased cortical BMD by $2.0 \%$ ( $\mathrm{P}=0.023$ vs. OVX; Table VI) and Cs.Th by $9.5 \%$ (P<0.001 vs. OVX). In contrast with C57BL/6J, estrogen treatment failed to significantly alter any above indices in BALB/c and Kunming mice except Tb.Th (13.7\%, P=0.001 vs. OVX; $14.9 \%, \mathrm{P}<0.001$; respectively). ICR was the least sensitive to estrogen treatment showing no significant alterations across all the parameters examined.

\section{Discussion}

OVX model mice have been widely used in the study of postmenopausal osteoporosis. Multiple lines of evidence have revealed that genetic factors serve a profound role in regulating 


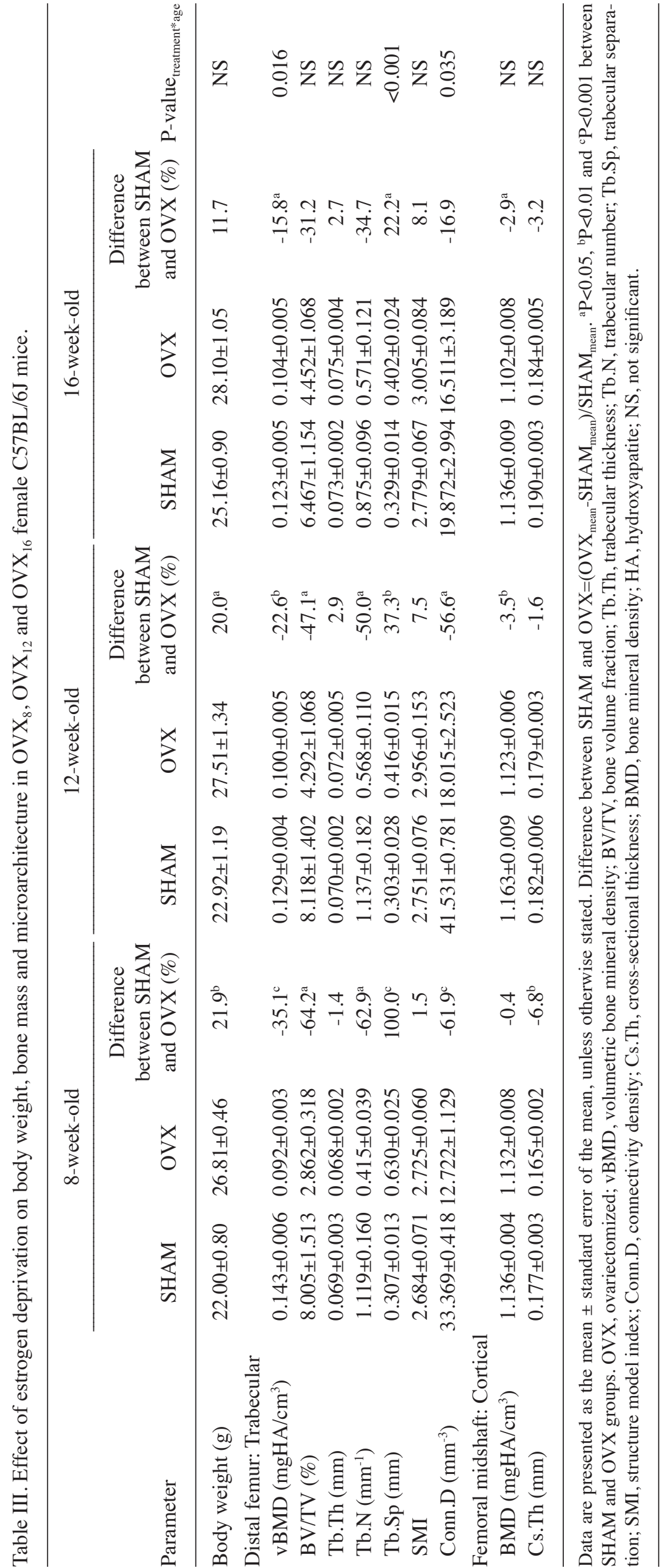


Table IV. Body weight, bone mass and microarchitecture in four inbred and outbred strains.

\begin{tabular}{|c|c|c|c|c|}
\hline Parameter & C57BL/6J $(n=6)$ & BALB/c $(n=6)$ & $\operatorname{ICR}(n=7)$ & Kunming $(n=6)$ \\
\hline Body weight (g) & $17.49 \pm 0.30^{\mathrm{b}-\mathrm{d}}$ & $23.16 \pm 0.85^{\mathrm{a}}$ & $29.20 \pm 0.43^{\mathrm{a}}$ & $36.29 \pm 0.82^{\mathrm{a}}$ \\
\hline \multicolumn{5}{|l|}{ Distal femur: Trabecular } \\
\hline vBMD $\left(\mathrm{mgHA} / \mathrm{cm}^{3}\right)$ & $0.137 \pm 0.004^{\mathrm{b}-\mathrm{d}}$ & $0.239 \pm 0.012^{\mathrm{a}}$ & $0.230 \pm 0.008^{\mathrm{a}}$ & $0.267 \pm 0.018^{\mathrm{a}}$ \\
\hline $\mathrm{BV} / \mathrm{TV}(\%)$ & $9.342 \pm 0.634^{\mathrm{b}-\mathrm{d}}$ & $26.236 \pm 1.920^{\mathrm{a}}$ & $20.161 \pm 1.844^{\mathrm{a}}$ & $29.749 \pm 3.233^{\mathrm{a}}$ \\
\hline Tb.Th (mm) & $0.074 \pm 0.002^{\mathrm{b}-\mathrm{d}}$ & $0.104 \pm 0.003^{\mathrm{a}, \mathrm{c}}$ & $0.091 \pm 0.003^{\mathrm{a}, \mathrm{b}, \mathrm{d}}$ & $0.102 \pm 0.003^{\mathrm{a}, \mathrm{c}}$ \\
\hline Tb.N $\left(\mathrm{mm}^{-1}\right)$ & $1.253 \pm 0.074^{\mathrm{b}-\mathrm{d}}$ & $2.535 \pm 0.175^{\mathrm{a}}$ & $2.182 \pm 0.144^{\mathrm{a}}$ & $2.881 \pm 0.236^{\mathrm{a}}$ \\
\hline Tb.Sp (mm) & $0.359 \pm 0.286^{\mathrm{b}, \mathrm{d}}$ & $0.270 \pm 0.017^{\mathrm{a}}$ & $0.301 \pm 0.025^{\mathrm{d}}$ & $0.218 \pm 0.014^{\mathrm{a}, \mathrm{c}}$ \\
\hline SMI & $2.559 \pm 0.033^{\mathrm{b}-\mathrm{d}}$ & $1.646 \pm 0.108^{\mathrm{a}}$ & $1.984 \pm 0.063^{\mathrm{a}}$ & $1.725 \pm 0.133^{\mathrm{a}}$ \\
\hline Conn.D $\left(\mathrm{mm}^{-3}\right)$ & $41.546 \pm 4.465^{\mathrm{b}-\mathrm{d}}$ & $81.648 \pm 5.149^{\mathrm{a}}$ & $73.165 \pm 4.898^{\mathrm{a}, \mathrm{d}}$ & $92.052 \pm 9.051^{\mathrm{a}, \mathrm{c}}$ \\
\hline \multicolumn{5}{|c|}{ Femoral midshaft: cortical } \\
\hline $\mathrm{BMD}\left(\mathrm{mgHA} / \mathrm{cm}^{3}\right)$ & $0.848 \pm 0.027^{\mathrm{b}-\mathrm{d}}$ & $1.119 \pm 0.011^{\mathrm{a}}$ & $1.151 \pm 0.006^{\mathrm{a}}$ & $1.129 \pm 0.009^{\mathrm{a}}$ \\
\hline Cs.Th (mm) & $0.138 \pm 0.002^{b-d}$ & $0.182 \pm 0.005^{\mathrm{a}, \mathrm{c}, \mathrm{d}}$ & $0.215 \pm 0.006^{\mathrm{a}, \mathrm{b}}$ & $0.210 \pm 0.009^{\mathrm{a}, \mathrm{b}}$ \\
\hline
\end{tabular}

Data are presented as the mean \pm standard error of the mean. ${ }^{\mathrm{a}} \mathrm{P}<0.05$ vs. $\mathrm{C} 57 \mathrm{BL} / 6 \mathrm{~J},{ }^{\mathrm{b}} \mathrm{P}<0.05 \mathrm{vs}$. BALB/c, ${ }^{\mathrm{c}} \mathrm{P}<0.05 \mathrm{vs}$. ICR and ${ }^{\mathrm{d}} \mathrm{P}<0.05 \mathrm{vs}$. Kunming. vBMD, volumetric bone mineral density; BV/TV, bone volume fraction; Tb.Th, trabecular thickness; Tb.N, trabecular number; Tb.Sp, trabecular separation; SMI, structure model index; Conn.D, connectivity density; Cs.Th, cross-sectional thickness; BMD, bone mineral density; HA, hydroxyapatite.

the balance of bone metabolism in mice $(14,20,21)$. In the present study, it was demonstrated that the peak of cancellous mass in C57BL/6J female mice was present at 8 weeks old. Mice subjected to OVX at 8 weeks old had marked cancellous bone loss, and OVX-induced cancellous bone loss was restored by estrogen treatment. The data also suggested that OVX-induced loss of cancellous bone may gradually decline with age in C57BL/6J female mice.

The BV/TV at distal femur in C57BL/6J mice has been shown to be greatest at 6 -weeks old and sequentially decline with age (22). The present study demonstrated an age-associated reduction in cancellous bone in $\mathrm{C} 57 \mathrm{BL} / 6 \mathrm{~J}$ female mice, as trabecular vBMD and BV/TV were greatest at 8 weeks old. Notably, it was revealed that OVX-induced loss of cancellous bone was associated with age, and the data indicated that the rate of trabecular bone loss in mice subjected to OVX at 8 weeks old was higher than that at 12 weeks old. In addition, there were no significant differences in cancellous bone alterations in mice subjected to OVX at 16 weeks old when compared with the SHAM group. These findings indicated that the effect of estrogen on regulating turnover of cancellous bone in C57BL/6J female mice may gradually decline with age. Further studies are necessary to explore cellular mechanisms underlying the reduced response to estrogen with age.

In contrast with cancellous bone, the results showed that an age-associated increase of cortical bone persisted throughout 8-16 weeks of age in C57BL/6J female mice. However, only a slight reduction in cortical bone, in an age-independent manner, was observed in those mice in response to OVX, suggesting that cortical bone was not sensitive to estrogen deprivation in $\mathrm{C} 57 \mathrm{BL} / 6 \mathrm{~J}$ female mice.

C57BL/6J mice are typically used to produce gene knockout and transgenic animals. A number of previous studies have identified bone loss when the ovariectomy timing was 2 months old in this strain $(23,24)$. However, C57BL/6J mice have been questioned as an ideal model for the study of postmenopausal osteoporosis as they have been found to be resistant to OVX-induced loss of bone. Bouxsein et al (14) previously discovered that 4-month-old C57BL/6J mice were resistant to OVX-induced trabecular bone deterioration in the proximal tibia. Iwaniec et al (15) demonstrated that no significant difference was observed between C57BL/6J OVX and SHAM groups in the distal femur cancellous BV/TV 3 months post-surgery. Klinck and Boyd (16) demonstrated that the majority of morphology parameters in the C57BL/6J femur and tibia were not statistically significant at 5 weeks post-ovariectomy. This data from previous research were obtained from mice subjected to OVX at the age of 12 or 16 weeks, which is consistent with the findings of the present study. The present study also revealed that alterations of cancellous bone in $\mathrm{C} 57 \mathrm{BL} / 6 \mathrm{~J}$ mice at the age of 8 weeks were greatest.

Previous studies have demonstrated that the skeletal response to OVX varied among inbred mice (14-16). This study extended the above by adding one inbred (BALB/c) and two outbred strains (ICR and Kunming), and all strains of mice were subjected to OVX at 8 weeks old. It was demonstrated that C57BL/6J mice were most sensitive to OVX-induced loss of bone among the four strains, exhibiting greater alterations in body weight, trabecular vBMD, BV/TV, Tb.N, Conn.D and Cs.Th. In contrast with previous results (14-16), the present study revealed that $\mathrm{C} 57 \mathrm{BL} / 6 \mathrm{~J}$ mice were the most sensitive to estrogen deficiency among the four strains. It should be noted that $\mathrm{Cs}$.Th, reflecting the cortical bone, decreased only in C57BL/6J mice. Contradicting results may be due to the age of the animals at OVX (previous studies using no less than 3-month-old C57BL/6J mice) and the duration of time elapsed following OVX (8 weeks). The various skeletal alterations during the 2-4 months old period caused by differing post-pubertal architectural development patterns among different strains may account for discrepancies arising from the different starting ages (25). It would be interesting to 


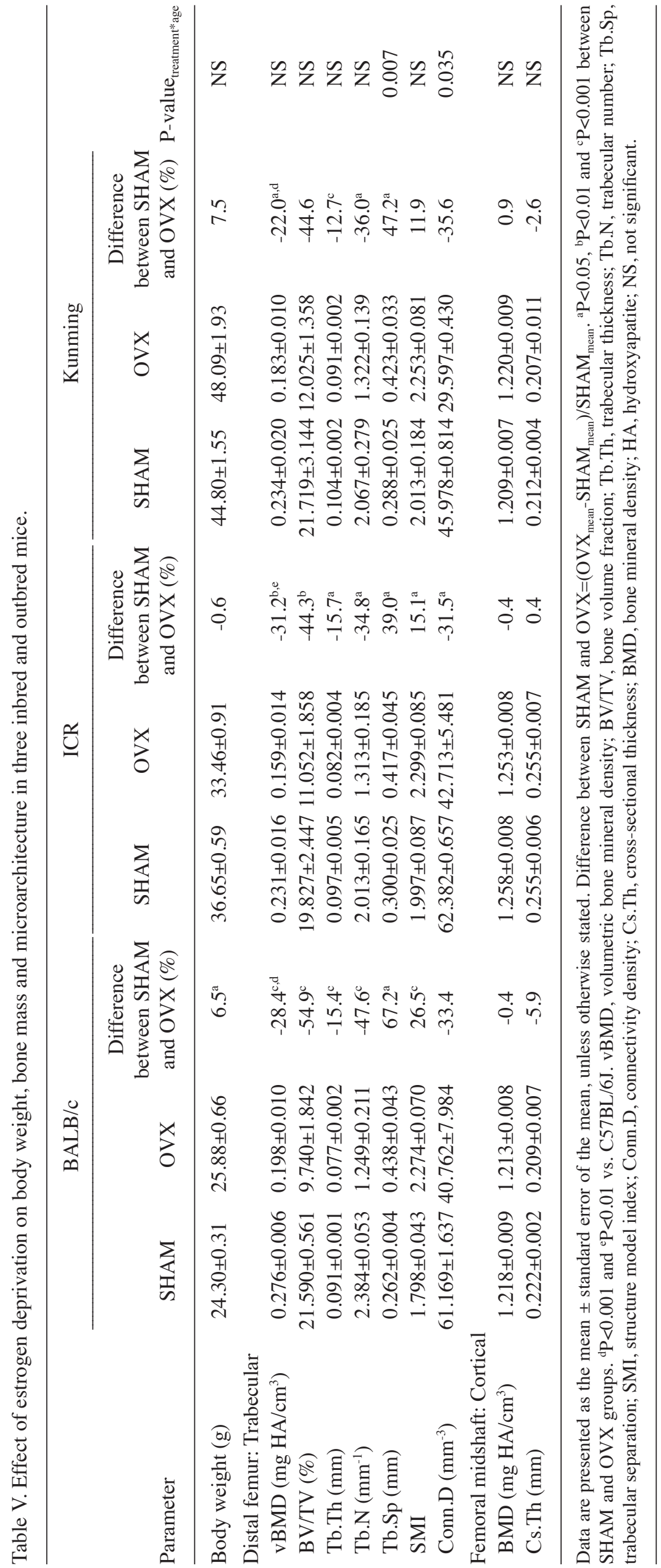




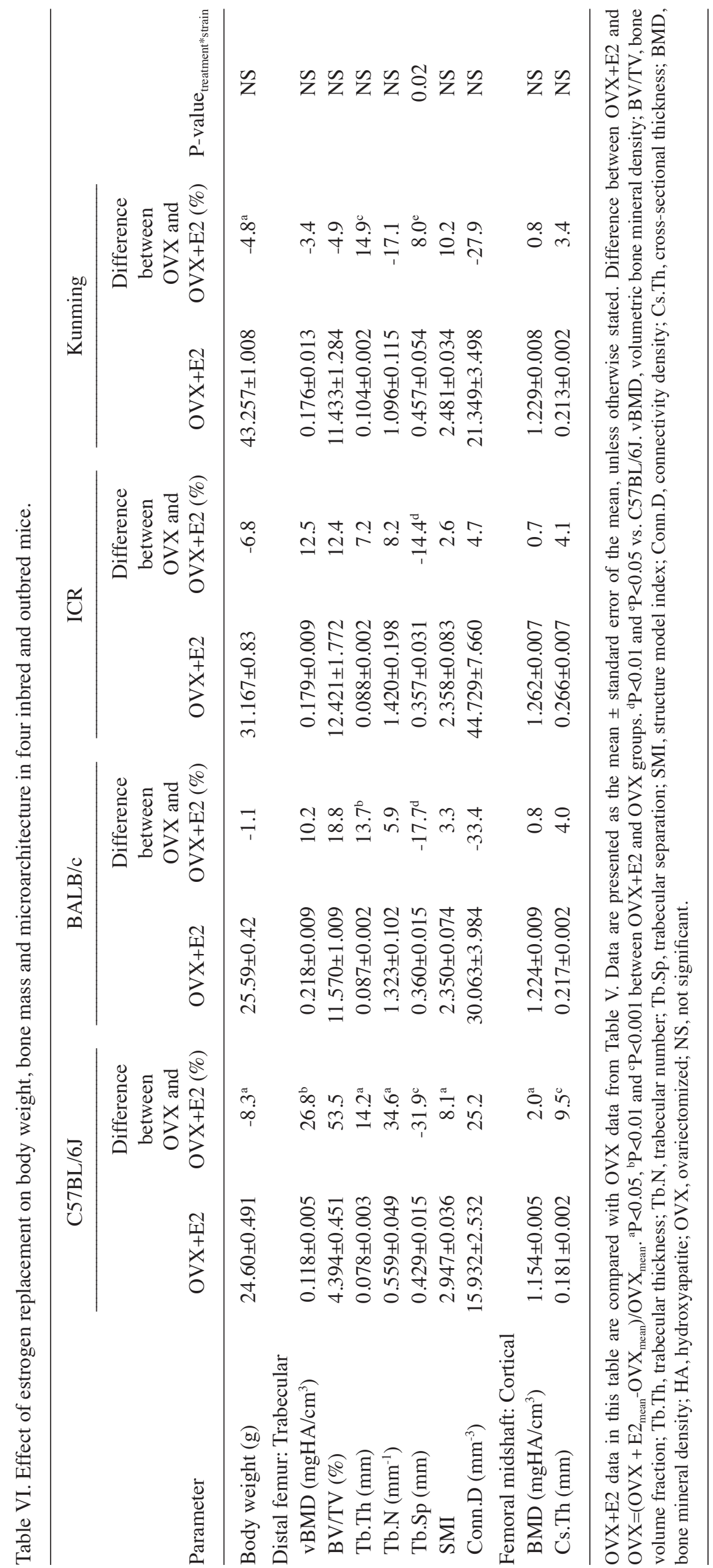


determine the underlying cellular mechanisms that determine the different strain-associated responses to estrogen deficiency by analysis of histomorphometry or biochemical markers.

E2 has been documented to improve bone quantity and miscrostructure both in mice and rats following OVX $(19,26)$. With respect to humans, estrogen therapy prevents postmenopausal bone loss (27). In the present study, it was revealed that skeletal responses to estrogen were strain-dependent where C57BL/6J improved most in regard to trabecular vBMD, BV/TV, Tb.Th, cortical BMD and Cs.Th. As for Conn.D, estrogen failed to significantly increase this as this index was thought to be irreversible when bone loss has occurred (28), as it was unclear whether the anabolic treatment parathyroid hormone restored any connectivity $(29,30)$.

The findings of the present study raise notable issues for selecting an animal model to study the mechanism of certain genes in postmenopausal osteopenia and evaluate the effectiveness of a novel candidate agent for treatment. Following OVX at 4 months old, C57BL/6J prostaglandin E2 receptor (one of the four prostanoid receptors) knockout mice exhibited protection against bone loss in femur and L4 vertebrae (31). However, when OVX was performed on 30-week-old female Col.1-PPAR $\gamma$ mice, ovariectomy-induced bone loss was accelerated (10). As the present results revealed that the factor age of C57BL/6J influenced the sensitivity of bone to OVX, the conclusions of a specific gene on osteoporosis must be identified with care. In addition, BALB/c, ICR and Kunming mice have been exploited in searching for anti-osteoporotic medicine, and drug testing results may be negative as the present study revealed that $\mathrm{C} 57 \mathrm{BL} / 6 \mathrm{~J}$ was the most sensitive to the anti-osteoporotic drug estrogen.

There are certain limitations associated with this study. First, only one bone (femur) was assessed to evaluate the extent of OVX-induced bone loss and response to estrogen. Second, only a single time point (8 weeks) after OVX was assessed and therefore the rate of bone loss was not assessed. Third, no histomorphometry or biochemical markers were performed, and thus it is impossible to observe the underlying cellular mechanisms that determine the different strain-associated responses to estrogen deficiency. In spite of these shortcomings, conclusions were made by $e x$ vivo analysis of femoral bone microarchitecture by $\mu \mathrm{CT}$, as the bone (femur), the postsurgery time (8 weeks) and method $(\mu \mathrm{CT})$ were the most commonly used in previous literature.

In conclusion, the results revealed that OVX-induced bone loss may be age- and strain-specific, which emphasizes the importance of appropriate selection of mouse strains and their age in postmenopausal osteoporosis research. It was demonstrated that C57BL/6J female mice subjected to OVX at 8 weeks old resulted in pronounced loss of bone that was sensitive to estrogen. Therefore, the present data may give novel insights into the age- and strain-associated effect of OVX in regulating turnover of bone in female mice, and this must be considered when using C57BL/6J mice as an animal model of postmenopausal osteoporosis.

\section{Acknowledgements}

The authors would like to thank Jason Kang for editing the manuscript. The present study was supported by the National
Science Foundation for Distinguished Young Scholars of China (grant no. 81125013) and National Natural Science Foundation of China (grant no. 81472116).

\section{References}

1. Jagtap VR, Ganu JV and Nagane NS: BMD and serum intact osteocalcin in postmenopausal osteoporosis women. Indian J Clin Biochem 26: 70-73, 2011.

2. Johnell $\mathrm{O}$ and Kanis JA: An estimate of the worldwide prevalence and disability associated with osteoporotic fractures. Osteoporos Int 17: 1726-1733, 2006

3. Cauley JA, Thompson DE, Ensrud KC, Scott JC and Black D: Risk of mortality following clinical fractures. Osteoporos Int 11: 556-561, 2000.

4. Frost SA, Nguyen ND, Center JR, Eisman JA and Nguyen TV: Excess mortality attributable to hip-fracture: A relative survival analysis. Bone 56: 23-29, 2013.

5. Reginster JY and Burlet N: Osteoporosis: A still increasing prevalence. Bone 38 (2 Suppl 1): S4-S9, 2006.

6. Francisco JI, Yu Y, Oliver RA and Walsh WR: Relationship between age, skeletal site and time post-ovariectomy on bone mineral and trabecular microarchitecture in rats. J Orthop Res 29: 189-196, 2011.

7. Liu XL, Li CL, Lu WW, Cai WX and Zheng LW: Skeletal site-specific response to ovariectomy in a rat model: Change in bone density and microarchitecture. Clin Oral Implants Res 26: 392-398, 2015.

8. Esteves CM, Moraes RM, Gomes FC, Marcondes MS, Lima GM and Anbinder AL: Ovariectomy-associated changes in interradicular septum and in tibia metaphysis in different observation periods in rats. Pathol Res Pract 211: 125-129, 2015.

9. Anderson JJ, Ambrose WW and Garner SC: Biphasic effects of genistein on bone tissue in the ovariectomized, lactating rat model. Proc Soc Exp Biol Med 217: 345-350, 1998.

10. Cho SW, Yang JY, Her SJ, Choi HJ, Jung JY, Sun HJ, An JH, Cho HY, Kim SW, Park KS, et al: Osteoblast-targeted overexpression of PPAR $\gamma$ inhibited bone mass gain in male mice and accelerated ovariectomy-induced bone loss in female mice. J Bone Miner Res 26: 1939-1952, 2011.

11. Hsu YH, Chen WY, Chan CH, Wu CH, Sun ZJ and Chang MS: Anti-IL-20 monoclonal antibody inhibits the differentiation of osteoclasts and protects against osteoporotic bone loss. J Exp Med 208: 1849-1861, 2011.

12. Jun AY, Kim HJ, Park KK, Son KH, Lee DH, Woo MH, Kim YS, Lee SK and Chung WY: Extract of Magnoliae Flos inhibits ovariectomy-induced osteoporosis by blocking osteoclastogenesis and reducing osteoclast-mediated bone resorption. Fitoterapia 83: 1523-1531, 2012.

13. Zhang Y, Wei L, Miron RJ, Shi B and Bian Z: Anabolic bone formation via a site-specific bone-targeting delivery system by interfering with semaphorin $4 \mathrm{~d}$ expression. J Bone Miner Res 30: 286-296, 2015.

14. Bouxsein ML, Myers KS, Shultz KL, Donahue LR, Rosen CJ and Beamer WG: Ovariectomy-induced bone loss varies among inbred strains of mice. J Bone Miner Res 20: 1085-1092, 2005.

15. Iwaniec UT, Yuan D, Power RA and Wronski TJ: Strain-dependent variations in the response of cancellous bone to ovariectomy in mice. J Bone Miner Res 21: 1068-1074, 2006.

16. Klinck $\mathbf{J}$ and Boyd SK: The magnitude and rate of bone loss in ovariectomized mice differs among inbred strains as determined by longitudinal in vivo micro-computed tomography. Calcif Tissue Int 83: 70-79, 2008.

17. Sabsovich I, Clark JD, Liao G, Peltz G, Lindsey DP, Jacobs CR, Yao W, Guo TZ and Kingery WS: Bone microstructure and its associated genetic variability in 12 inbred mouse strains: microCT study and in silico genome scan. Bone 42: 439-451, 2008.

18. Kara FM, Doty SB, Boskey A, Goldring S, Zaidi M, Fredholm BB and Cronstein BN: Adenosine A(1) receptors regulate bone resorption in mice: Adenosine A(1) receptor blockade or deletion increases bone density and prevents ovariectomy-induced bone loss in adenosine A(1) receptor-knockout mice. Arthritis Rheu 62: 534-541, 2010.

19. Modder UI, Riggs BL, Spelsberg TC, Fraser DG, Atkinson EJ, Arnold R and Khosla S: Dose-response of estrogen on bone versus the uterus in ovariectomized mice. Eur J Endocrinol 151: 503-510, 2004. 
20. Beamer WG, Donahue LR, Rosen CJ and Baylink DJ: Genetic variability in adult bone density among inbred strains of mice. Bone 18: 397-403, 1996.

21. Li CY, Schaffler MB, Wolde-Semait HT, Hernandez CJ and Jepsen KJ: Genetic background influences cortical bone response to ovariectomy. J Bone Miner Res 20: 2150-2158, 2005.

22. Glatt V, Canalis E, Stadmeyer L and Bouxsein ML: Age-related changes in trabecular architecture differ in female and male C57BL/6J mice. J Bone Miner Res 22: 1197-1207, 2007.

23. Duque G, Huang DC, Dion N, Macoritto M, Rivas D, Li W, Yang XF, Li J, Lian J, Marino FT, et al: Interferon- $\gamma$ plays a role in bone formation in vivo and rescues osteoporosis in ovariectomized mice. J Bone Miner Res 26: 1472-1483, 2011.

24. Wang F, Wang PX, Wu XL, Dang SY, Chen Y, Ni YY, Gao LH, Lu SY, Kuang Y, Huang L, et al: Deficiency of adiponectin protects against ovariectomy-induced osteoporosis in mice. PLoS One 8: e68497, 2013.

25. Buie HR, Moore CP and Boyd SK: Postpubertal architectural developmental patterns differ between the L3 vertebra and proximal tibia in three inbred strains of mice. J Bone Miner Res 23: 2048-2059, 2008.

26. Thompson DD, Simmons HA, Pirie CM and Ke HZ: FDA Guidelines and animal models for osteoporosis. Bone 17: 125S-133S, 1995.
27. Bansal N, Katz R, de Boer IH, Kestenbaum B, Siscovick DS, Hoofnagle AN, Tracy R, Laughlin GA, Criqui $\mathrm{MH}$, Budoff MJ, et al: Influence of estrogen therapy on calcium, phosphorus and other regulatory hormones in postmenopausal women: The MESA study. J Clin Endocrinol Metab 98: 4890-4898, 2013.

28. Campbell GM, Buie HR and Boyd SK: Signs of irreversible architectural changes occur early in the development of experimental osteoporosis as assessed by in vivo micro-CT. Osteoporos Int 19: 1409-1419, 2008.

29. Sato M,Zeng GQ and Turner CH: Biosynthetic human parathyroid hormone (1-34)effects on bone quality in aged ovariectomized rats. Endocrinology 138: 4330-4337, 1997.

30. Sato M, Westmore M, Ma YL, Schmidt A, Zeng QQ, Glass EV, Vahle J, Brommage R, Jerome CP and Turner $\mathrm{CH}$ : Teriparatide [PTH(1-34)] strengthens the proximal femur of ovariectomized nonhuman primates despite increasing porosity. J Bone Miner Res 19: 623-629, 2004.

31. Zhang M, Feigenson M, Sheu TJ, Awad HA, Schwarz EM, Jonason JH, Loiselle AE and O'Keefe RJ: Loss of the PGE2 receptor EP1 enhances bone acquisition, which protects against age and ovariectomy-induced impairments in bone strength. Bone 72: 92-100, 2015. 